\title{
An Ultra Low Phase Noise W-Band GaAs-Based PHEMT MMIC CPW VCO
}

\author{
Ping-Yu Chen, Zou-Min Tsai, Shey-Shi Lu, and Huei Wang \\ Dept. of Electrical Engineering and Graduate Institute of Communication Engineering \\ National Taiwan University, Taipei, Taiwan, ROC \\ Phone: +886-2-23635251 ext.317 Fax:+886-2-23638247 E-mail: hueiwang@ew.ee.ntu.edu.tw
}

\begin{abstract}
A W-band voltage control oscillator (VCO) using 0.1- $m$ AlGaAs/InGaAs/GaAs PHEMT MMIC technology with ultra low phase noise is presented. This VCO demonstrated an operation frequency centered at 97 GHz with a tuning range of $2 \mathrm{GHz}$ and an output power of 1 $\mathrm{mW}$. The measured single side-band phase noise is $\mathbf{- 8 8}$ $\mathrm{dBc} / \mathrm{Hz}$ at $1 \mathrm{MHz}$ offset. To the best of our knowledge, this phase noise performance is not only the best among the previously reported results for HEMT MMIC VCO at this frequency, but also rivals those for most VCOs using HBTs.
\end{abstract}

\section{INTRODUCTION}

Oscillators are important components in communication systems. In the past, most high frequency oscillators are based on IMPATT and Gunn diodes. Though they demonstrated good power performance, the special processes are not compatible with other MMIC components. With the MMIC technologies advanced in the recent years, millimeter-wave MMIC oscillators operated at W-band frequencies implemented based on HEMT and HBT devices were reported [1]-[7]. HEMT devices have the advantages of higher gain for high frequency operation and therefore quite a few MMIC VCO were reported [1]-[5]. On the other hand, HBTs has inherent low device $1 / f$ noise characteristics, oscillators based on InP-based HBT to achieve low phase noise performance [6]-[7].

In this paper, a low phase noise W-band MMIC HEMT $\mathrm{VCO}$ is presented. This VCO demonstrated an operation frequency centered at $97 \mathrm{GHz}$ with $2-\mathrm{GHz}$ tuning range and $1-\mathrm{mW}$ output power. The most significant feature of this VCO is that the measured phase noise is $-88 \mathrm{dBc} / \mathrm{Hz}$ at $1-\mathrm{MHz}$ offset. Table I summarizes the previously reported performances and features of MMIC VCOs in W-band. It can be observed that the phase noise performance reported in this paper is not only the best among the previously reported W-band HEMT VCOs, but also rivals those of most HBT-based VCOs except the one in [8], which reported a superior phase noise performance of $-95 \mathrm{dBc} / \mathrm{Hz}$ for $1-\mathrm{MHz}$ offset at $104 \mathrm{GHz}$.

\section{Device Characteristics AND MMIC Process}

The HEMT device used in this design is TRW 0.1- $\mu \mathrm{m}$ high linearity AlGaAs/InGaAs/GaAs PHEMT MMIC process. The HEMT device has a typical unit current gain cutoff frequency $\left(f_{T}\right)$ of higher than $100 \mathrm{GHz}$ and maximum oscillation frequency $\left(f_{\max }\right)$ of greater than 250 $\mathrm{GHz}$ at $2-\mathrm{V}$ drain bias, with a peak de transconductance $\left(G_{m}\right)$ of $600 \mathrm{mS} / \mathrm{mm}$. The gate-drain breakdown voltage is $6 \mathrm{~V}$, and the drain current at peak transconductance $\left(I_{d s p k}\right)$ at $2-\mathrm{V}$ drain-source voltage is $600 \mathrm{~mA} / \mathrm{mm}$. This MMIC process also includes thin-film resistors, MIM capacitors, spiral inductors, and air-bridges. The wafer is thinned to 4-mil for the gold plating of the backside and reactive ion etching via holes are supported.

\section{VCO DESIGN}

The W-band oscillator circuit schematic diagram and photograph are shown in Fig. 1. The chip size is $1.5 \mathrm{~mm}$ $\times 1 \mathrm{~mm}$. The HEMT device used in this design is TRW $0.1-\mu \mathrm{m}$ high linearity $\mathrm{AlGaAs} / \mathrm{InGaAs} / \mathrm{GaAs}$ PHEMT MMIC process. A HEMT device with four-finger $80-\mu \mathrm{m}$ gatewidth is employed and grounded coplanar waveguide (GCPW) is used as the transmission medium in this design. Two transmission lines connected to two source terminals and one transmission line to gate are dedicated to decide the operation frequency and form the positive feedback. Via holes are placed on the ground metals to suppress the undesired parallel plate modes of the GCPWs. In addition, airbridges are used at each discontinuity to suppress the undesired slot mode excitation. All the passive structures were characterized by a full-wave EM analysis to eliminate the uncertainty of passive element models.

\section{MEASURED RESULTS}

This VCO was measured via on-wafer probing and the output signal was monitored through the spectrum analyzer by using a sub-harmonic mixer to down-convert the W-band RF signal to IF band. By tuning the gate 
voltage from -0.3 to $0.4 \mathrm{~V}$, the frequency and the power of the output signals were read from the spectrum analyzer. Fig. 2 shows the oscillation frequency and output power as functions of gate voltage for $\mathrm{V}_{\mathrm{d}}=4 \mathrm{~V}$. The tuning range is about $2 \mathrm{GHz}$ centered at $97 \mathrm{GHz}$ and the average output is $-1 \mathrm{dBm}$. The phase noise is directly estimated from the spectrum analyzer as shown in the spectrum plot of Fig. 3, which indicates the phase noise to be $-88 \mathrm{dBc} / \mathrm{Hz}$ at $1-\mathrm{MHz}$ offset. This is not only the best phase noise result among the previously reported W-band HEMT VCOs [1]-[5], but also rivals those of the HBTbased VCOs [6]-[7].

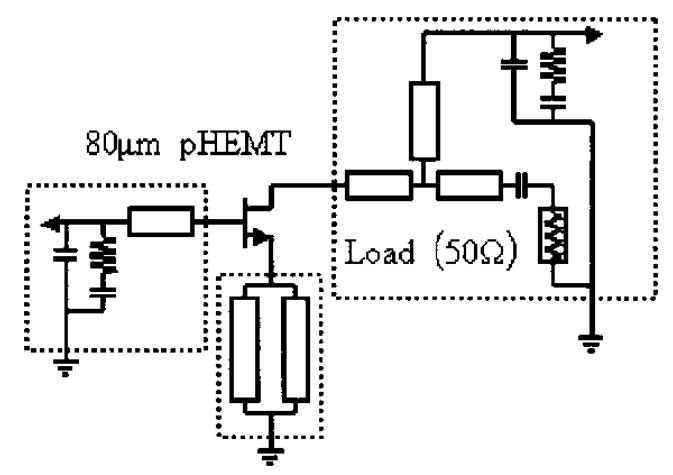

(a)

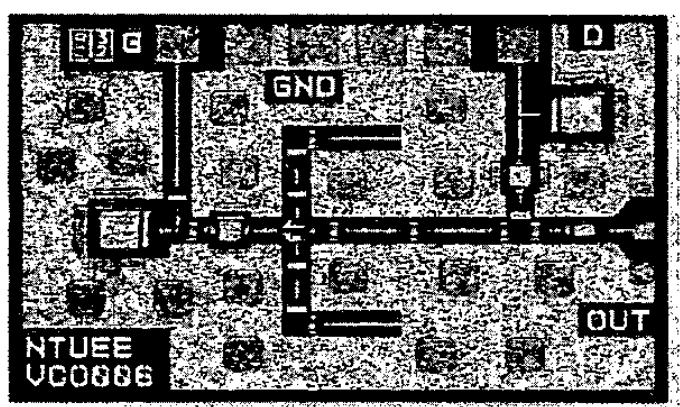

(b)

Fig. 1. The (a) circuit schematic diagram, (b) chip photograph (chip size $1.5 \mathrm{~mm} \times 1 \mathrm{~mm}$ ), of the W-band MMIC CPW VCO.

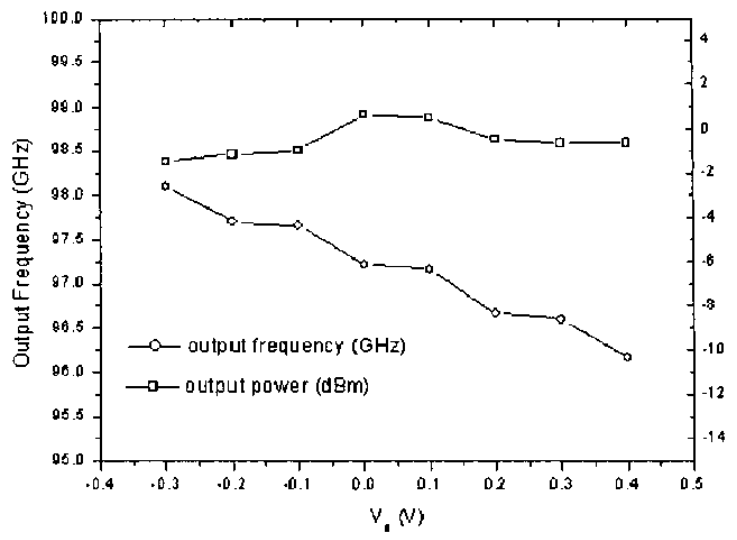

Fig. 2. The measured oscillation frequency and output power as functions of gate voltage for $V_{d}=4 \mathrm{~V}$.

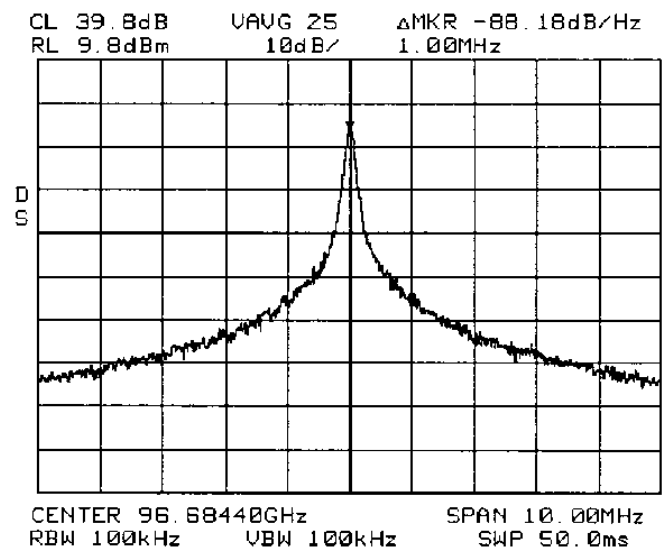

Fig. 3. The measured spectrum plot of the W-band MMIC CPW VCO. The VCO oscillates at $96.7 \mathrm{GHz}$ with phase noise of $-88 \mathrm{dBc} / \mathrm{Hz}$ at $1-\mathrm{MHz}$ offset.

\section{DISCUSSIONS}

Although this W-band GCPW VCO utilized the same HEMT device $(0.1-\mu \mathrm{m}$ GaAs-based PHEMT MMIC process provided by TRW) and a similar circuit architecture as the $\mathrm{W}$-band microstrip-line VCO reported in [1], the phase noise performance is significantly different from each other. The reason is described briefly as the following.

The phase noise of an oscillator is related to two noise sources, which are the up-converted low-frequency noise and the multiplied noise near by the carrier frequency [9]. The up-converted low-frequency noise is due to the nonlinearity of the transistor that can be treated as a mixer. The power incident into the gate $P_{i}$, and the feedback 
power out of the matching circuit $P_{f}$ can be analyzed via the harmonic balance (HB) analysis by defining a feedback loop of the gate and drain of the PHEMT device. It is observed that there is a trade off between output power and phase noise. On the other hand, the multiplied noise near by the carrier frequency is related to the open loop quality factor $Q$, which is a function of the angular frequency derivatives of the magnitude and phase of the open loop gain [9]. One can conclude that the phase noise will be improved as Q increases.

Comparing the microstrip-line VCO reported in [1] with this CPW VCO the Q-factors are similar in both designs and therefore the up-converted low-frequency noise power will dominate the phase noise performance. Since the small signal open loop gain of the microstrip-line VCO is higher than that of this CPW VCO, the microstrip-line VCO operated at a higher saturation condition and cause higher $P_{i}$ with a higher near carrier noise power. Due to a lower $P_{i}$, the CPW VCO exhibits a better phase noise performance but lower output power.

\section{CONCLUSWN}

In this paper, an ultra low phase noise W-band MMIC CPW VCO using GaAs-based HEMT is presented. The measured tuning range of this $\mathrm{VCO}$ is $2 \mathrm{GHz}$ with an average output power of $-1 \mathrm{dBm}$ over its tuning range. A phase noise of $-88 \mathrm{dBc} / \mathrm{Hz}$ at $1-\mathrm{MHz}$ offset was achieved, which is the best result among the previously published VCOs in this frequency regime.

\section{ACKNOWLEDGEMENT}

This work is supported in part by National Science Council (NSC 89-2213-E-002-178, NSC 89-2219-E-002042), and Research Excellence Program funded by Department of Education (ME 89-E-FA06-2-4) of Republic of China. The chip is fabricated by TRW foundry service through CIC of Taiwan. The authors would like to thank Mr. G. G. Boll of GGB Corporation for his providing the $\mathrm{W}$-band $\mathrm{RF}$ probes. Thanks also go to Hong-Yeh Chang and Kun-You Lin for their help on the chip testing.

TABLE I

THE PREVIOUSLY REPORTED PERFORMANCE AND FEATURES OF W-BAND MMIC

\begin{tabular}{|c|c|c|c|c|c|c|c|c|c|}
\hline Author & $\begin{array}{l}\text { Huei Wang } \\
\text { et al., [1] }\end{array}$ & $\begin{array}{l}\text { K. Bangert } \\
\text { et al., [2] }\end{array}$ & $\begin{array}{l}\text { S. Kudszus } \\
\text { et al., [3] }\end{array}$ & $\begin{array}{c}\text { H. J. } \\
\text { Siweris et } \\
\text { al., [4] }\end{array}$ & $\begin{array}{l}\text { V. Radisic } \\
\text { et al., [5] }\end{array}$ & $\begin{array}{c}\text { K.W. } \\
\text { Kobayashi } \\
\text { et al., [6] }\end{array}$ & $\begin{array}{l}\text { Y. Baeyens } \\
\text { et al., [7] }\end{array}$ & $\begin{array}{c}\text { Uchida, } \mathrm{K} . \\
{[8]}\end{array}$ & This work \\
\hline Device & $\begin{array}{l}0.1 \mu \mathrm{m} \\
\text { PHEMT }\end{array}$ & $\begin{array}{l}0.15 \mu \mathrm{m} \\
\text { PHEMT }\end{array}$ & $\begin{array}{l}0.15 \mu \mathrm{m} \\
\text { PHEMT }\end{array}$ & $\underset{\text { HEMT }}{0.12 \mu \mathrm{m}}$ & \begin{tabular}{|c|}
$0.1 \mu \mathrm{m}$ \\
AllnAs/Galn \\
As/lnP \\
HEMT \\
\end{tabular} & InP-HBT & $\ln \mathrm{P}-\mathrm{HBT}$ & $\begin{array}{c}\text { InGaP/InGa } \\
\text { As HBT }\end{array}$ & $\begin{array}{l}0.1 \mu \mathrm{m} \\
\text { PHEMT }\end{array}$ \\
\hline Approach & $\begin{array}{l}\text { Negative } \\
\text { resistance }\end{array}$ & $\begin{array}{l}\text { Negative } \\
\text { resistance }\end{array}$ & $\begin{array}{l}\text { Negative } \\
\text { resistance }\end{array}$ & Feedback & $\begin{array}{l}\text { Negative } \\
\text { resistance }\end{array}$ & $\mid \begin{array}{c}\text { Push-Push } \\
2^{\text {nd }} \\
\text { harmonic }\end{array}$ & Differential & $\begin{array}{l}\text { Negative } \\
\text { resistance }\end{array}$ & $\begin{array}{l}\text { Negative } \\
\text { resistance }\end{array}$ \\
\hline $\begin{array}{l}\text { Freq. } \\
(\mathrm{GHz})\end{array}$ & $\begin{array}{c}90.5 \\
\text { (power) } \\
92 \\
\text { (low noise) }\end{array}$ & 94 & 94 & 77 & 80 & 108 & 94 & 104 & 97 \\
\hline $\begin{array}{l}\text { Tuning } \\
\text { Range }\end{array}$ & $\begin{array}{c}800 \mathrm{MHz} \text { (low } \\
\text { noise) } \\
600 \mathrm{MHz} \\
\text { (power) }\end{array}$ & $\begin{array}{c}8 \mathrm{GHz} \\
\text { (electrical) } \\
18 \mathrm{GHz} \\
\text { (removing } \\
\text { airbridge) }\end{array}$ & $4.5 \mathrm{GHz}$ & $2 \mathrm{GHz}$ & $\begin{array}{l}7 \mathrm{GHz} \\
\text { (Varactor- } \\
\text { tune) }\end{array}$ & $\begin{array}{c}2.73 \mathrm{GHz} \\
\text { (Varactor- } \\
\text { tune) }\end{array}$ & $13 \mathrm{GHz}$ & & $2 \mathrm{GHz}$ \\
\hline $\begin{array}{l}\text { Output power } \\
(\mathrm{dBm})\end{array}$ & $\begin{array}{c}7.6 \text { (low } \\
\text { noise) } \\
8.8 \text { (power) } \\
\end{array}$ & 7.78 & 2 (max.) & 7.5 & 12.5 & 0.92 & -3 & -3.4 & 0.7 \\
\hline $\begin{array}{c}1 \mathrm{MHz} \text { offset } \\
\text { phase noise } \\
(\mathrm{dBc} / \mathrm{Hz})\end{array}$ & -68.2 & -67 & -71 & -78 & - & -88 & -85 & -95 & -88 \\
\hline
\end{tabular}




\section{REFERENCES}

[1] Huei Wang, K.W. Chang, T. H. Chen, K. L. Tan, G. S. Dow, B. Allen and J. Berenz, "Monolithic W-band VCOs using pseudomorphic AlGaAs/InGaAs/GaAs HEMTs," 1992 IEEE GaAs IC Symp. Dig., pp. 47-50.

[2] A. Bangert, M. Schlechtweg, M. Lang. W. Haydl, W. Bronner, T. Fink, K. Köhler and B. Raynor, "W-band MMIC VCO with a large tuning range using a pseudomorphic HFET," 1996 IEEE MTT-S International Microwave Symposium Digest, San Francisco, pp. 525-528, 1996.

[3] S. Kudszus, W. H. Haydl, M. Neumann, A. Bangert and A. Hülsmann, "Subharmonically injection locked $94 \mathrm{GHz}$ MMIC HEMT oscillator using coplanar technology," 1998 IEEE MTT-s International Microwave Symposium Digest, pp. 1585-1588, 1998.

[4] H. J. Siweris, H. Tischer, T. Grave and W. Kellner, "A Monolithic W-band HEMT VCO with feedback topology," 1999 IEEE MTT-S International Microwave Symposium Digest, pp. 17-20, 1999.

[5] V. Radisic, L. Samoska, K. Micovic, M. Hu, P. Janke, C. Ngo and L. Nguyen, "80 GHz MMIC HEMT VCO," IEEE
Microwave and Wireless Component Letter, vol. 11, no. 8, pp. 326-327, Aug. 2001.

[6] K. W. Kobayashi, A. K. Oki , L. T. Tran, J. Cowles, A. Gutierrez-Aitken, F. Yamada, T. Block and D. C. Streit, "A 108-GHz InP-HBT Monolithic Push-Push VCO with low phase noise and wide tuning bandwidth," IEEE J. SolidState Circuits, vol. 34, no. 9, pp. 1225-1232, 1999.

[7] Y. Baeyens, C. Dorchky, N. Weimann, Q. Lee, R. Kopf, G. Georgiou, John-Paul Mattia, R. Hamm and Y. K. Chen, "Compact InP-Based HBT VCOs with a wide tuning range at W- and D-band," IEEE Trans. on Microwave Theory and Tech., vol. 48, no. 12, pp. 2403-2408, Dec. 2000.

[8] Uchida, K.; Aoki, I.; Matsuura, H.; Yakihara, T.; Kobayashi, S.; Oka, S.; Fujita, T.; Miura, A. "104 and $134 \mathrm{GHz}$ InGaP/InGaAs HBT oscillators" 21st Annual Gallium Arsenide Integrated Circuit (GaAs IC) Symposium Dig., pp. $237-240,1999$

[9] Behzad Razavi, "Analysis, modeling, and simulation of phase noise in monolithic voltage-controlled oscillators" 1995 IEEE Custom Integrated Circuits Conference Proceedings, pp. 323-326, May 1-4 1995 